This is a post-print (author's final draft) of an article in the journal Musicae Scientiae (2009), 4B, pp. 99-118. [Original page numbers between square brackets]. Details of the definitive version are available at http://intlmsx.sagepub.com/content/13/1_suppl/99.abstract?patientinformlinks=yes\&legid=spmsx;13/1_suppl/99

\title{
Similarity perception as a cognitive tool for musical sense- making: deictic and ecological claims
}

\author{
Mark Reybrouck \\ University of Leuven, Section of musicology \\ Blijde Inkomststraat 21, PO Box 3313 \\ 3000 Leuven, Belgium \\ mark.reybrouck@arts.kuleuven.be
}

\begin{abstract}
[99] This is a programmatic paper. It elaborates on the concept of similarity as a cognitive tool for sense-making in music. Taking as a starting point the definition of similarity as a relational concept it tries to provide a description in terms of standard and goal that can be applied to the delimitation of elements as well as to the comparison of these elements with each other. As such it focusses on three major topics: (i) the delimitation of elements, (ii) the comparison of these elements to themselves (self-reference) and to each other, and (iii) an operational framework for the delimitation of these elements. The latter is considered from the position of deixis and ecological perception, relying on the "deictic" act of mental pointing to elements that are eligible for deliberate attention as well as on the "ecological" principles of event perception and
\end{abstract}


cognitive economy. It is possible, further, to conceive of pointing as an internal construction of an external operation, and to consider pointing as a predication process which can be applied to focal points as well as to events with at least some extension through time.

\section{INTRODUCTION}

There are several approaches to similarity perception in music. Depending upon the goal setting of the music user it can be used (i) as a heuristic device for music retrieval purposes, allowing the searcher to find a positive match between what he/she is looking for and what has been found; (ii) it can be used also as a tool for sense-making, allowing the listener to experience a kind of recognition in listening to complex music; and (iii) it can be used as a syntactic category in order to build up coherence over time.

There is, further, a dynamic tension between similarity as a structural feature of the sounding music [100] and similarity as perceived by the listener, somewhat analogous to Lerdahl's (1988) distinction between "composing" and "listening grammars" which stresses the distinction between intended and perceived structure of the music.

This paper is about musical sense-making and the role of similarity perception in this process. It conceives of listeners as epistemic systems that build up semiotic linkages with the sounding world (Reybrouck, 2005a, 2006). These linkages determine the categories of perception and cognition that are available to the system, but to the extent that they can be modified, the system can learn to make new distinctions and create new observational categories or "observables", as Cariani coins them (Cariani, 2003). As such, listeners can be considered as 
adaptive epistemic systems that determine the semantic relations with their external world through processes of selection and delimitation and by giving semantical weight to these distinctions.

Musical knowledge, in this view, can be generated as a tool for adaptation to the sonic world. Music, in fact, can be conceived as a universal phenomenon with adaptive power. According to Miller (2000, see also Trehub 2003), it exemplifies many of the classic criteria for complex human adaptation: (i) no culture in any period of recorded history has been without music (universality); (ii) the development of musical abilities is orderly; (iii) the ability is widespread in the sense that almost every normal adult can appreciate music and carry a tune (basic perceptual and performing skills); (iv) adults can recognize thousands of melodies, implying specialised memory; (v) special-purpose cortical mechanisms are involved; (vi) there are analogues in the signals of other species such as songbirds, gibbons, and whales, raising the possibility of convergent evolution; and (vii) music can evoke strong emotions which implies receptive as well as productive adaptation.

Music, thus, is not to be seen as an evolutionary luxury, but is grounded in the "ecological" approach to knowledge generation which studies the human cognitive and perceptual apparatus in the service of survival and orientation in the environment (Shepard, 1984, and Reybrouck, 2001 for a musical analogy). As such, it goes beyond a merely structural description of the music, calling forth a process-like description of "coping" with the music as environment. What counts, in this approach, is not merely the sounding music in its objective qualities, but also the music as perceived and listened to. Listeners, accordingly, are supposed to make sense out of the music as a challenging environment. To do so, they should rely on basic mechanisms of information extraction with the perception of similarity as a major strategy. It is an approach that fits in with an 
adaptive model of perceptual categorisation that allows the assignment of salience to events that have adaptive value and that requires the negotiation of the ongoing activities of delimitation, discrimination and association of events (Edelman, 1989).

The question, however, is on what listeners select to focus. Do they rely on innate and wired-in mechanisms of reactivity to sounding stimuli or do they call forth higher-level processes that relate to [101] levels of epistemic autonomy? Should we consider acts of deliberate attention, which are to a great extent arbitrary and subjective, or acts of obligatory attention that are triggered merely by perceptual saliency? According to Wiggins, there are three levels in coping with sounds: physics provide the basics on which general audition is founded, survival provides the selection force that perpetuates general audition and human associative memory and learning provides the rest (2007, p. 318). As such there is a basic tension between "nature" and "nurture" with both innate and acquired mechanisms of sense-making (Reybrouck, 2008). The question, however, should not be stated in terms of a choice between stimulus-driven, bottom-up processes or conceptually-driven, top-down processes, as both of these processes are continually in play in the perception and interpretation of music in its aural form (see e.g. Bregman, 1990, with his distinction between primitive and schematic perceptual processes). Even though one may distinguish these two aspects of perception in a number of ways, both are routinely active and interacting with one another.

In this paper it is argued that listeners are able to learn to distinguish and to make sense out of these distinctions and observables with a corresponding shift from focal attention to acts of recognition and identification. In order to provide an operational framework for these claims, three major contributions are discussed below: (i) the deictic approach of mental pointing, (ii) the ecological 
approach to sense-making and (iii) the role of similarity perception in this approach.

The "deictic approach" covers the aspect of how musical events can denote something and be delimited from each other. Arguing for a dynamic-vectorial approach to sense-making, it allows to describe listening experiences in a realtime listening situation using concepts from linguistic theory, semiotics, the philosophy of language and logic. The "ecological approach" stresses that music listening is a real-world activity which should be studied with empirical methods. Here, general questions about the constituents of perception come into play which are analysed by means of several important concepts such as events, invariants and transformation. The "similarity perception" approach, finally, treats this process as an important element of perception in general and music perception in particular, with a stratification of the concept in different degrees of similarity. The major advantage of these approaches is the real-time and contextual embedding of the listening situation rather than providing merely a post-hoc description of music as an artefact which proceeds mostly out of the time of actual unfolding.

\section{DEIXIS AND THE ACT OF POINTING}

The delimitation of sounding elements involves processes of focal attention that can be approached from the domain of deixis and indexical devices. This means that we should conceive of the listening process as a referential exchange between the music and the listener and that we can rely on linguistic [102] means in an attempt to allocate the points of focal attention in time and space. These linguistic means involve a number of deictic terms which "pick out" or "point to" things in relation to the participants in a speech situation (Clark, 1978). To speak of the sound of "this" clarinet is an example. And 
referring back to the sound we just heard as "that sound", or simply "that", is another one. That sound is only obvious for the participants of the previous listening situation who shared an act of joined attention.

These deictic terms are related to Peirce's notions of index and indexical sign, which are signs that point to something else. They may be distinguished from other signs in having no significant resemblance to their objects, in referring to individuals, single units, single collections of units, or single continua, and in directing the attention to their objects by blind compulsion (Peirce, 1960: 172). A such, they are used in the same way as Bühler (1934) talks about "pointing words" as opposed to "naming words" (Lyons, 1982). They go back to the distinct fields of meaning which Bühler called the field of pointing and the symbolic field (1982). The former holds a dynamic-vectorial approach to the world and is directive in nature; the latter relies on distancing and polarisation between the cogniser and the world. Speaking of a violin in general, for instance, does not imply the physical presence of an actual instrument. It can be conceived at a merely symbolic level — as can be done with all meaningful units of a linguistic lexicon. Listening to the sound of a violin, on the contrary, holds a dynamic approach that captures the temporal unfolding of the articulation of the sound.

Deictic procedures and expressions are thus related to the field of pointing. They focus the hearer's attention towards a specific element of the deictic space (Ehlich, 1982). As such they realise a form of joint attention, the sharing of overlap in the focal attention of the parties of a referential exchange. The means for doing this comprise a set of procedures, varying from such evolved linguistic devices as anaphora (referring back to text) and deixis (referring back to context) to simple ostensive pointing (Bruner, 1983, p. 68, see also Kita, 2003, for an extensive overview). 
All these devices have in common that they are helpful in singling out the things that are eligible for denotation. This is most obvious from the use of "pragmatic anaphora" which is a linguistic expression - mostly a deictic one — such as a demonstrative pronoun that is accompanied by a pointing gesture which indicates to the hearer the intended referent (e.g. I bought that [pointing] yesterday). In order to interpret the pragmatically controlled pronoun that, the listener must pick out the intended referent in his/her visual field, perhaps with the aid of the speaker's pointing gesture (Jackendoff, 1987, p. 148). In a more linguistic sense, the concept of anaphora is used for referring back (catadeixis) to things just treated (this, that...) or things that are to be treated immediately (anadeixis) (Ehlich, 1982). In order to do this, one must have access to the flow of discourse as a whole, where parts may be re-taken up and anticipated To quote Bühler: "[the] whole must be accessible to sender and receiver, so that a wandering is possible, comparable to the passing of one's gaze over an [103] optically present object. (...) The adequate production and reception of any piece of music, for example, requires not exactly this, but something similar." (1982: 21)

This brings us to the field of deixis, as Bühler (1934) coined the term. He presented as a main thesis that deictic expressions refer to a deictic field of language whose zero point (the Origo) is fixed by the person who is speaking (I), the place of utterance (here), and the time of utterance (now). As such, deixis, is a source of reference that locates individual elements in context, rather than simply tagging them. It has its origin within the speaking situation, with the meaning of deictic expressions depending crucially on when, where and by whom they are used. As such, an ordinary speech situation can be systematised in terms of personal, spatial and temporal deixis (Fillmore, 1982). Deictic expressions, therefore, have to be defined with reference to the speech event, its 
participants and its settings in order to allow an operational description of space/time moments and their relations to the position and time of utterance (Fillmore, 1972).

The deictic framework has proven to be fruitful in linguistics. It is possible, however, to translate it also to the realm of music. The perception of sonic events and their foregrounding/backgrounding, their categorisation, and specifying their interrelations are all clearly necessary aspects of music perception of which deictic concepts are appropriate and helpful. The fact that music has both a diachronic and a synchronic aspect makes this more the case rather than less.

Music, further, is a temporal and sounding art which can be dealt with "in time" and "out-of-time". The first approach proceeds in real-time and is coperceptual with the sounding music being presented to the senses. It holds a dynamicvectorial approach hat refers to real-time listening and that can be operationalised as a referential exchange between the music and the listener. It is also related to the "experientialist" approach to music perception which relies on actual experience of sounding stimuli (see Reybrouck, 2005b for an extensive overview). The "out-of-time" approach, on the other hand, relies on memory and representation with the music being present only at a representational level of virtuality. This is a "conceptual-symbolic" approach that does not rely on sounding stimuli but on their symbolic counterparts. It calls forth the role of internal modelling and mental representations which imply processes of abstraction, distancing and polarisation between the listener and the sounding stimuli (Reybrouck, 2006).

The mental representations, further, may be continuous or discrete, but the latter are the more economical. They relinquish the particularities and idiosyncrasies 
of the sensory experience in favour of forms of conceptualisation which process the incoming information in a more discrete way. As such they are important cognitive tools that transcend the perceptual experience and that allow the listener to do "autonomous" processing — without "peripheral connection" through the senses (Langacker, 1987) — and to go beyond temporal and spatial constraints. They have adaptive value in transcending the frame of the present and in providing means for anticipatory behaviour of organisms in general. To [104] quote Edelman: "the development of short-term memory that was related to the succession of events and signals ... consolidated the evolutionary advantage provided by an integrated "mental image", allowing the assignment of salience to events in terms of adaptive values." (1989, p. 186).

\section{POINTING AS A PREDICATION PROCESS}

The act of (mental) pointing has descriptive power. It enables the listener to single out the noteworthy and to delimit the entities that are eligible for isolation and individuation in the field of experience. There are, however, different kinds of pointing. According to Bühler (1934) there are three kinds of them: demonstratio ad oculos, anaphora and deixis ad phantasma. The first involves direct demonstration — an act of gestural pointing — the others are derived forms of pointing: they use the same deictic word anaphorically (e.g. "this") or point in the imagination, replacing the index finger as the natural tool of pointing by other deictic aids.

The act of singling out is most important. It is exemplified most typically in the use of pragmatic anaphora, which is a powerful tool that has some relevance for the perception of similarity. It is used traditionally for referring back (catadeixis) to things just treated in discourse (this, that...) or things that are immediately to be treated (anadeixis) (Ehlich, 1982). 
The singling out of entities, further, is dependent upon definite reference which implies cognitive prerequisites such as being able to pick out an object for someone else. According to Clark, this implies three major suppositions about the objects to denote: they must have an independent existence apart from the speaker and the listener, they must have the possibility to be individuated and they must belong to classes $(1978$, p. 91). This latter supposition brings about the description of the act of pointing in a logical sense, allowing the listener to assign some general description to the particular thing that is denoted. It is the basic assumption of a logical judgment as exemplified in a proposition ( $\mathrm{p}, \mathrm{q}, \mathrm{m}$ ) which assigns a predicate variable $(\mathrm{a}, \mathrm{b}, \mathrm{c} . .$.$) to an object variable (\mathrm{x}, \mathrm{y}, \mathrm{z} \ldots)$ and which can be formally represented as a 'one-place predicate' ( 'ax': $\mathrm{x}$ has the quality a). To give an example: a particular sound has the property of being bright ('ax': the sound (a) has the property (x)).

This propositional approach has a number of advantages. It strips down the idiosyncrasies and particularities of sounding elements and conceives of them in terms of propositional functions (Reybrouck, 2004). Referring again to the clarinet example, it is possible to conceive of a typical sound from clarinet a, clarinet $b$, or clarinet $c$, each with their particular characteristics, as against conceiving of the sound of a clarinet in general as a more-encompassing category. The latter entails a broadening of the mathematical concept of "denotative" function - which "denotes" a particular value of the function- to the logical concept of "propositional" function, as advocated by Whitehead and [105] Russell: "Let $\phi x$ be a statement containing a variable and such that it becomes a proposition when $x$ is given any fixed determined meaning. The $\phi x$ is called a "propositional function", it is not a proposition, since owing to the ambiguity of $x$ it really makes no assertion at all." (1968, p.14). As such, it 
makes a difference whether we speak of "the" sound of a clarinet $(\phi x)$ as against saying that "this" particular and actual sound is the sound of a clarinet $(\phi a)$.

The propositional approach, further, should transcend the limitations of traditional subject-predicate constructions which have proved to be inadequate as evidenced by the shortcomings of categorical grammars (Levelt, 1974) which are reducible to well-known linguistic categories - such as noun, verb or other syntactic categories - and the existence of languages without copula. The use of a copula (a word used to link the subject of a sentence with a predicate), e.g. does not exhaust all possible relations between the subject and the predicate. As such, it is possible and arguable, to enlarge the categories of subject and predicate to other categories such as predicate and arguments which can be treated formally as variables. This means that both the argument ( $\mathrm{x}$ or a) and the function $(\phi)$ can be filled in deliberately, allowing the listener to select and focus at will in delimiting the argument to which a function should be assigned. Conceiving of sounding elements as functions involves an act of generalisation, filling in the arguments involves an act of particularisation. As such, there is a tension between the particularities of the sounding elements and the economy of labelling and representation.

The dynamic-vectorial approach of mental pointing holds a position in between. It can try to capture the temporal unfolding of the sounding music both in a kind of snapshot or as a continuous gesture that keeps step with the articulation through time. As such, it is somewhat related to Langacker's distinction between "processual" and "episodic nominalisations": processual predications follow the temporal evolution of a situation and involve a continuous series of states that represent different phases of the process as occupying a continuous series of points in conceived time. The span of time during which the evolution is tracked 
is referred to as its temporal profile (1987, p. 244). Episodic nominalisations, on the contrary, refer to just one single instance of the process.

This brings us to the temporal extension of the elements that are eligible for delimitation and which seems to be dependent both on the structural characteristics of the sounding elements as well as on the reference time span of observation. Taking the actual unfolding of music in time, the listener can select and (mentally) point to delimited segments of this unfolding, extending the position in a time-series from discrete slices of time to larger temporal spans. As Godøy puts it, it is possible to establish a means of obtaining knowledge at different temporal levels (a single tone, a phrase, an entire movement) and "to move between different musical objects of different sizes, to "zoom" and "pan" both in and out and sideways and "filter out" different kinds of information. " (1997, p. 40). As such, the temporal window can be very small or more encompassing with a possible transition from "high-frequency" or "highresolution" processing — in the range of about 10 milliseconds - to perceptual [106] units - in the range of 2-3 seconds - which allow event identification over time (Wittmann \& Pöppel, 1999-2000; Wittmann, 1999). It brings us to the notion of musical events, which mostly have a clearly defined time of beginning and of ending and which have a gross temporal patterning as well. As such they hold a position between "invariance" and "change".

\section{EVENT PERCEPTION AND THE ECOLOGICAL APPROACH}

The above-mentioned claims provide a deictic framework for the denotation and delimitation of sounding elements. Starting from acts of deliberation attention, it is possible to gather the focal points the listener is pointing at and to allocate these point in space and time. Each of these points can be considered as a zero point in a deictic field, as the centre of a referential exchange between the music 
and the listener. Each new act of denotation, then, involves a shift from one zero point to another. Or put in other terms: the dynamic-vectorial approach allows the listener to conceive of the unfolding of the sounding music in terms of a wandering origo. It illustrates the operational power of the deictic framework.

In order, however, to have some real-world validity, the framework must be grounded in empirical research that refers to data-based studies with two major questions: what do listeners mentally point at when they listen, and what is the motivation behind their acts of focal attention and delimitation? There has been a vast body of data-based research on the extraction of criterial and musical features from sounding music (see the special volumes of Musicae Scientiae (2007, Forum 4A) and of Music Perception (2001, 3)) with a major focus on similarity perception and categorisation in listening to music. Most of these studies focus on music-structural features such as motivic and thematic similarity, key derivation and meter induction rather than on sonic events. Yet, it seems that simple auditory cues which are not specific to music, play an important role in similarity perception and categorisation as well (Ziv \& Eitan, 2007).

The contributions of Deliège on cue abstraction should be mentioned here (Deliège, 2001a, b). Conceiving of "cues" as salient elements that are prominent at the level of musical surface, she argues for a similarity/difference model of real-time listening that is helpful in attracting the listener's attention to some focal points that act as waymarkers for the marking out of musical time. The abstracted cues give access to memory for musical time as reference points that are organised during the process of listening (Deliège, 1995). Especially promising in this approach is the aim to develop an account which is congruent with real-time perception and which is not restricted to particular types of musical structures. 
As such, there is the possibility to broaden the research and to go beyond the constraints of the traditional parameters of music theory. The contributions from ecological perception can be especially [107] helpful here. They are related to the mechanism of "event perception" and "cognitive economy" as exemplified by the distinction between everyday listening and musical listening (Gaver, 1993). Taking the example of a driving car, it is possible to pay attention to the pitch, the loudness and the timbre of the perceived sound and also to the way these parameters change with time. This is "musical listening" with the perceptual dimensions and attributes of concern having to do with the sound itself and the way the dimensions are used in its creation. It is possible, however, to notice also that the sound is made by a car with a large and powerful engine that is approaching very quickly from behind. This is an example of "everyday listening" with the experience of listening to events rather than to sounds. The perceptual dimensions and attributes which are of concern correspond to those of the sound-producing event and its environment, and not to those of the sound itself.

The distinction is somewhat analogous also to Handel's differentiation between categorical and auditory perception. The former relies on "discrete" processing with the "event" being heard directly and the "acoustic properties" of the sound being recovered only from memory. In auditory perception the "acoustic properties" are heard directly, with the perceptual events being deduced (1989, p. 274). The experience of time is critical in this distinction: auditory perception involves real-time processing, categorical perception relies also on memory and proceeds partially out-of-time.

The question, however, remains, how musical events are defined, identified and extracted from the acoustic signal. Event perception is well studied in the visual 
modality, but our understanding of this in the acoustic modality is far more limited. Work in auditory scene analysis (ASA) (Bregman, 1981, 1990) and in computational auditory scene analysis (CASA) (Rosenthal \& Okuno, 1998; Wang \& Brown, 2006) and in music information retrieval (MIR) (Downie, 2003, Müller, 2007) have to deal with questions like event identification, trying to come up with things like edge detection mechanisms for sounds, somewhat analogous to Marr's (1987) computational investigation into the representation and processing of visual information. Bregman (1990) and his intellectual successors may serve as a starting point here as they drew an analogy between the perception of auditory and visual scenes and described a coherent framework for understanding the perceptual organisation of sound.

This brings us to the topic of deixis as categorisation and the role of event perception and cognitive economy (see Reybrouck, 2005a). There is, in fact, a difference between the "recognition" of a sounding object or event as a discrete entity and the "experience proper" of its sonorous articulation through time. The recognition of events allows us to conceive of them in a propositional way and to specify an event perceptually in terms of "invariants".

The extraction of invariants, further, pertains to either static or dynamic features of stimulus information. As such there is a distinction between structural or transformational invariants (Shaw et [108] al., 1996; Michaels \& Carello, 1981; Bartlett, 1984) with "structural" invariants referring to features that do not change over time or that change rather slowly, and "transformational" invariants referring to styles of change (Shaw \& Pittenger, 1987). Both kinds of invariants underlie the perception of events which can be defined in operational terms as "something happening to something", with the "something happening" being specified by transformational invariants and the "something" to which something is happening by structural invariants (Michaels and Carello, 1981, p. 
26). The typical sound of a string instrument is an example of this "something", the different sound-producing actions on the strings (bowing, plucking with a finger or a plectrum) may illustrate the "something happening".

Transformational invariants specify the change that is occurring in or to the object, whereas structural invariants describe the object by itself. Recognition of the sound of a clarinet, for example, is a structural invariant, the specific articulation of the sound is transformational. As such it is possible to specify an event (E) perceptually when both the transformational (TI) and the structural invariant (SI) are available to be detected. An event, then, can be specified in a propositional way when the two-variable function E(TI, SI) can be evaluated (Shaw et al., 1996). To give an example: an event involving a bouncing ball might be denoted as $\mathrm{E}(\mathrm{TI}=$ bouncing, $\mathrm{SI}=$ ball $)=$ bouncing ball. The distinction is somewhat analogous to the distinction of a value of a function $\mathrm{y}$ at point $\mathrm{x}$ and the change in value around point $x$, i.e. the value of the first derivative of $y$.

The example is illustrative of event perception. It involves top-down processing of time-varying complex acoustic properties of sound which can be considered as higher-order variables. Events - as invariant patterns - are sequences of stimuli which are extended in time and which can be described in terms of their invariants. They behave as basic building blocks which function as units in perception and memory. As such they call forth an "ecological approach" to memory phenomena, which is related to the concept of schemata and the three core ideas of event perception: (i) the units of perception and memory are temporally extended "events"; (ii) the basis of perception and memory is the pick-up of invariants over time; and (iii) perception and memory are essentially veridical. These ideas are very similar to what is commonly known as the event perception hypothesis (Gibson 1966, 1979; Bransford \& McCarrell, 1977) which states that there is no clear dividing line between the traditional domains 
of perception and memory, and that the units of memory or perception can be greatly extended in time. "Events", in this view, are the appropriate units of analysis, whether they are "fast"-as in perception - or "slow"-as in memory (Bartlett, 1984).

Events, further, can be defined in an intuitive way as "things that happen", involving "changes in objects or collections of objects" (Michaels \& Carello, 1981). It is obvious that the concepts of invariants - structural and transformational — and of events are tightly intertwined: the former act as a kind of "glue" that "unitises" sequences of stimulus information into coherent events (Bartlett, 1984). [109] They make it possible to describe events both at a glance and in their temporal unfolding, providing both a discrete and an analog description of invariant patterns over time.

The perception of events has adaptive value as well: event schemes are cognitive schemes which are helpful in making sense of the environmental world. What listeners consider to be an "acoustic" or "auditory event", however, is dependent on the way they schematise the physical structures in the sonic environment and on the way these structures are considered to be relevant to their adaptive efforts to succeed in their interaction. As such, we can conceive of music cognition as a schematising process that ecologises the stuff of the world (events) either to render it more assailable by the organisms or to accommodate the organism to its environment (Shaw \& Hazelett, 1986). This means that knowledge, as an instrument of adaptation, is not concerned with the representations of a "real world" but is a tool in the pursuit of equilibrium and for steering clear of external perturbations and internal contradictions. It is centred around the two fundamental principles of "assimilation" and "accommodation" in the sense that the mind primarily assimilates, that is, perceives and categorises experience in terms of what is already known (Piaget, 
1936, 1937). Cognitive assimilation thus comes about when a cognizing organism fits an experience in a conceptual structure it already has. Only if the result of this process creates a perturbation, a review is initiated that may lead to an accommodation.

This is a purely biological way of thinking which led Piaget to a theory of knowledge that formulates the conceptual structure of knowledge as the product of active knowers who shape their thinking to the constraints they experience. This biological concept of adaptation, however, can be transposed to the realm of cognition, and music cognition, in this view, can be considered also as a tool for adaptation to the sonic world (Reybrouck, 2001, 2008).

\section{SIMILARITY PERCEPTION AND THE CONCEPT OF SIMILARITY}

The idea of event perception is an important conceptual tool. It allows the listener to make sense out of the sounding flux by identifying and recognizing sounding events. As such, it is closely related to the concept of similarity perception, which, according to Deliège, addresses various degrees of equivalence such as identity, repetition and invariant/variant relationship (2001a, p. 233). The concept of similarity, however, is ill-defined. According to the strictness of its definition, it is possible to distinguish between identity, similarity, analogy, homology, isomorphy and even more possibilities. The concepts of identity and invariance, however, promise significant operational power both as descriptive and explanatory terms.

There is, first, a major distinction between full and partial identity, running the whole gamut between full identity and complex nonrelationship. The distinction has been exemplified already in music theory by approaches such as Reti's, which distinguished between four stages of structural formation: [110] imitation, 
varying, transformation and indirect affinity. Imitation is defined as literal repetition of shapes; varying involves a change of shapes in a well traceable manner; transformation creates essentially new shapes though preserving the original substance; and indirect affinity produces an affinity between independent shapes through contributory features (Reti, 1961, p. 240). The distinction has been exemplified again in the structural approach of distributive linguistics with an emphasis on analytical "procedures of division" that take a starting figure and its possible transformations and that look for similarity between the figure and its transformation. A major emphasis therein has been, however, on repetition in the domains of pitch and time, besides the application of more complex operations such as permutations, addition and deletion and other aspects of grouping (Ruwet, 1972). It is preferable, however, to broaden the similarity detection approach from mere musical parameters such as melody and rhythm to events with more real-world validity and to introduce the concepts of invariance and transformation.

The concept of invariance is an ecological concept that has adaptive power. It allows the listener to perform perceptual categorisations and to assign temporal unfoldings to a subset of time objects which are identifiable and recognizable as such (Reybrouck, 2004). These time objects can be delimited and being compared to each other, making it possible to conceive of them in terms of standard and goal.

The acts of delimitation should go beyond the level of casual attention. which implies that the elements should have a sufficient level of identity in order to be identified and recognized. It reminds us of the delimitation of units as advocated in "systems theory" (Weiss, 1971). 
Elements, in this view, should be determined by three criteria: they are composite fragments of the universe, they should retain sufficient identity over time and they should deserve a name. It is possible, however, to go beyond this nominal description of delimited elements and to conceive of them in terms of "subjects" in a broader sense. Such a subject, according to Kuroda, is a primary unit of knowledge that is the content of a judgment: "That to which a judgment affirms or denies the attribution of a property is called the subject of the judgment, and that which the judgment affirms or denies of the subject is called its predicate." (1976, p. 2). As such, it is possible to focus on the sounding events as subjects as well as on their properties. This is basically the distinction between "ecological" and "auditory" listening (see above) with the former referring basically to the sounding events and the latter to their properties.

Similarity perception, further, can be approached from two positions: the delimitation of sounding elements and the comparison of these elements to each other. As such, it combines the deictic and ecological approach of denotation and delimitation with a relational approach. It is possible, in fact, to conceive of similarity as a relational concept which can be defined in terms of comparison between a target and a standard somewhat analogous to the usage of these terms in similarity measurement theories (see Tversky, 1977) and category learning experiments (Medin \& Schaffer, 1978; Nosofsky, 1988).

[111] When the target is identical with the standard, however, there is full identity. It is possible, therefore, to include also the act of denotation in the relational approach, which means that something can be equated with itself (see Cambouropoulos, 2001, for an interesting overview). This is merely a kind of self-reference or reflexivity in a mathematical sense, but it is also the hermeneutical extension of the act of pointing that conceives of "something as something", which is an important tool for exploratory listening and for the 
delimitation of elements in acts of deliberate attention. A further step is to identify this something at another place or time with at least some physical distinction between the things that are denoted. This involves a separate actuation of the same thing which is a very important distinction that can be dealt with in deictic terms. An additional distinction is the difference between internal and external similarity relations with the relations being identified in the same work (internal) or between distinct and autonomous musical entities (Deliège, 2007).

In order to elaborate on these claims I propose a stratification of three levels of similarity. I conceive of them in terms of 0 th, 1 st and 2 nd order similarity:

- 0 th order similarity is merely self-referential. It has a relation of identity with itself and is self-reflexive in a mathematical sense.

- 1 st order similarity introduces a physical separation between at least two actuations of denoted elements that are compared to each other with an additional constraint that the denoted elements belong to the same musical work or sounding environment. As such this kind of similarity relies on actual experience and memory.

- 2nd order similarity introduces an epistemic cut between the 0th and 1st order similarity and elements that are outside the actual experience. As such it involves representation and imagery as well as long term memory.

I consider the $0^{\text {th }}$ and $1^{\text {st }}$ order similarity to be of major importance for the experiential approach to music listening. They share the coperceptual aspect of at least one of the actuations of the denoted elements and are related to the field of pointing rather than to the symbolic field. The $2^{\text {nd }}$ order similarity is only partially perceptually grounded. It proceeds also out of the time of actual unfolding of the sounding music. As such, it is related also to the symbolic field of meaning. The major advantage of this stratification is its operational power. 
$0^{\text {th }}$ order similarity has denotative power in gathering the things the listener selects for focal attention. As such, it has its starting point in the acts of attention rather than in the structural description of the music. $1^{\text {st }}$ and $2^{\text {nd }}$ order similarity, on the other hand, are relational in their basic claims. They go beyond mere mental pointing in providing cognitive tools for a structural description of the sounding music.

\section{SIMILARITY PERCEPTION AS A COGNITIVE TOOL}

[112] In listening to music, it is possible to distinguish between the structural characteristics of the music and the structuring by the listener (Reybrouck, 2005a). Especially at the higher levels of cognitive processing, there seems to be a lot of subjectivity. Yet, there are universal processing mechanisms that go beyond the idiosyncrasies of individual and subjective reactions to the sound. As a rule this applies to the lower levels of processing - with the risk of psychobiological reductionism - and the ecological levels of coping with the world. There are, however, lawful commonalities at higher levels of perceptual processing as well. This seems to suggest that perception is not merely a primitive data-driven process which works independently of top-down influences. The Gestalt laws of perception are illustrative of this point. According to Pomerantz (1986) there are no fewer than 114 Gestalt laws for object perception, suggesting that they can hardly be built into a primitive datadriven process. This sheer number simply calls forth higher levels of processing and information organisation, although some rules for recognizing the natural world's regularities seem to be embodied in the hardware of our brains (see Reybrouck, 2008 for an extensive overview).

The same holds true for similarity perception, which can be dependent upon both data-driven aspects of perceptual saliency as well as upon acts of deliberate 
attention. It is possible, however, to go beyond the level of extraction of salient features and to conceive of similarity perception as a cognitive tool for music knowledge construction as well. Similarity perception, in this view, should be related to the principle of cognitive economy. It allows the listener to "recognize" something and to rely on previous experience as a standard for comparison. Depending on the focal adjustment of the current experience, it is possible to take account of all or only a part of the facets of the actual experience. This is the basic tension between particularity and generality which can be used either for enhancing the actual experience or for performing mental computations.

Two mental operations are of major importance here: to "distinguish" and to "recognize". They exemplify the transition from the deictic process of mental pointing (to distinguish) which implies presentation to the senses, to recognition which implies an act of representation at a mental level. To the extent that this recognition takes a symbolic form, it is possible to deal with music at a computational level. As such, there is some analogy with the traditional approach to musical syntax which is relational in its basic claims.

\section{CONCLUSION}

This paper has argued for a deictic and ecological approach to similarity perception in music. Starting from a conception of listeners as epistemic adaptive systems, it conceives of music knowledge [113] construction as the outcome of learning to make new distinctions and observables. As such, it calls forth processes of delimitation and denotation which can be considered as acts of mental pointing. It is argued, further, that there is a continuity between delimitation and recognition, in the sense that identification of salient events 
relies on acts of self-reference, where recognition requires comparison between something and something else.

The major contribution of this paper is a broadening of the conception of musical similarity from a rather reductionist approach in terms of musical parameters to an ecological approach of sounding events. It has been stated already that views from music theory are not always compatible with views from cognitive psychological approaches, and empirical studies (see Lamont \& Dibben, 2001, for an overview) have shown also that listeners may use surface attributes rather than "deep structure" of the music, as evidenced in musical modes of listening. As such, this paper offers some conceptual tools for an operational description of the act of mental pointing relying on the field of deixis and indexical devices and the ecological approach of event perception and cognitive economy. These claims are programmatic to a great extent, but they can suggest directions for future research. Two major topics seem to be of interest: to assess empirically the elements to which listeners mentally point in a listening task and to assess the mental operations that are carried out on these elements. The former should transcend the limitations of parametric thinking and systems based approaches that lay constraints on the kind of elements that are selected for comparison. Rather than starting from well-defined standards for comparison with a target, future research should focus also on "things that are eligible for denotation" and that can act as standards for comparison.

\section{ACKNOWLEDGEMENTS}

I wish to thank the anonymous reviewers whose comments were very helpful in improving the overall quality of this paper.

\section{References}


Bartlett, J. (1984). Cognition of complex events: visual scenes and music. In W. Crozier \& A. Chapman (eds). Cognitive Processes in the Perception of Art (pp. 225-51). Amsterdam - New York - Oxford: North-Holland.

Bransford, J. \& N. McCarrell (1977). A sletch of a cognitive approach to comprehension: some thought about understanding what it means to comprehend. In P. Johnson-Laird \& P. Wason (eds). Thinking. Readings in Cognitive Science (pp. 377-99). Cambridge - London - New York Melbourne: Cambridge University Press.

Bregman, A. (1981). Asking the "what for" question in auditory perception. In M. Kubovy \& J. Pomerantz (eds). Perceptual Organization (pp. 99-118), Hillsdale: Erlbaum.

Bregman, A. (1990). Auditory Scene Analysis: dThe Perceptual Organization of Sound, London, Cambridge, MA: MIT Press.

Bruner, J. (1983). Child's Talk. Learning to Use Language. Oxford: Oxford University Press.

Bühler, K. (1934). Sprachtheorie: Die Darstellungsfnktion der Srache. Jena: Fischer.

Bühler, K. (1982). The Deictic Field of Language and Deictic Words (Transl.). In R. Jarvella \& W. Klein (eds). Speech, Place, and Action. Studies in Deixis and Related Topics (pp. 9-30). Chichester - New York: John Wiley. Cambouropoulos, E. (2001). Melodic Cue Abstraction, Similarity, and Category Formation. Music Perception, 18, 3, 347-70.

Cariani, P. (2003). Cybernetic systems and the semiotics of translation. In S. Petrilli (ed). Translation Translation (pp. 349 - 37). Amsterdam: Rodopi. Clark, E. (1978). From Gesture to Word: On the natural History of Deixis in Language Acquisition. In J. Bruner, J. \& A. Garton (eds). Human Growth and Development (pp. 85-120). Oxford: Clarendon Press. 
Deliège, I. (1995). Cue-Abstraction and Schematization of the Musical Form.

Scientific Contributions to General Psychology, 14, 11-28.

Deliège, I. (2001a). Introduction: Similarity Perception <--> Categorization <--> Cue Abstraction. Music Perception, 18, 3, 233-43.

Deliège, I. (2001b), Prototype Effects in Music Listening: An Empirical Approach to the Notion of Imprint. Music Perception, 18, 3, 371-407.

Deliège, I. (2007). Similarity relations in listening to music: How do they come into play? Musicae Scientiae. Discussion Forum 4A, 9-29.

Downie, J. (2003). Music information retrieval. In B. Cronin, Annual Review of Information Science and Technology 37 (pp.295-340). Medford, NJ: Information Today Books.

Edelman, G. (1989). The remembered present. A biological theory of consciousness. New York: Basic Books.

Ehlich, K. (1982), Anaphora and Deixis: Same, Similar, or Different? In R.J. Jarvella \& W. Klein (eds). Speech, Place and Action. Studies in Deixis and Related Topics (pp.315-38). Chichester - New York - Brisbane - Toronto Singapore: John Wiley \& Sons.

Engelkamp, J. (1981). Experimentelle Psychosemiotik: Wahrnehmung Vorstellung - Begriff. Zeitschrift für Semiotik, 289-333.

Fillmore, Ch. (1972). Ansätze zu einer Theorie der Deixis. In: F. Kiefer (Ed), Semantik und generative Grammatik. I (pp. 147-74). Frankfurt/M: Athenäum Verlag.

Fillmore, Ch. (1982). Towards a Descriptive Framework for Spatial Deixis. In R. Jarvella \& W. Klein (eds). Speech, Place, and Action. Studies in Deixis and Related Topics (pp.31-59). Chichester - New York: John Wiley.

Gaver, W. (1993). What in the world do we hear? An ecological approach to auditory event perception. Ecological Psychology, 5 (1), 1-29.

Gibson, J. (1966). The Senses Considered as Perceptual Systems. London: Allen \& Unwin. 
Gibson, J. (1979). The Ecological Approach to Visual Perception. Boston -

Dallas - Geneva - Illinois - Hopewell - New Jersey - Palo Alto - London: Houghton Mifflin Company.

Godøy, R.I. (1997). Formalization and Epistemology. Oslo: Scandinavian University Press.

Handel, S. (1989). Listening. An Introduction to the Perception of Auditory Events. Cambridge - London: MIT Press.

Jackendoff, E. (1987). Consciousness and the Computational Mind. Cambridge (Ma) - London: MIT Press.

Kita, S. (2003). Pointing. Where Language, Culture, and Cognition Meet. Mahwah (N.J.): Erlbaum.

Kurodi, S.-Y. (1976). Subject. In M. Shibatani (ed). Syntax and Semantics, Vol.5. Japanese Generative Grammar (p. 5). New York - San Francisco London: Academic Press.

Lamont, A. \& N. Dibben. (2001). Motivic Structure and the Perception of Similarity. Music Perception, 18, 3, 245-74.

Langacker, R. (1987). Foundations of cognitive grammar, Vol. 1. Stanford CA: Stanford University Press.

Lerdahl, F. (1988). Cognitive constraints on compositional systems. In J.

Sloboda (ed), Generative Processes in Music (pp. 231-59). Oxford: Clarendon Press.

Levelt, W. (1974). Formal Grammars in Linguistics and Psycholinguistics.Vol. II, Applications in Linguistic Theory. The Hague - Paris: Mouton. Lyons, J. (1982). Deixis and Subjectivity: Loquor, ergo sum? In R. Jarvella \& W. Klein (eds). Speech, Place, and Action. Studies in Deixis and Related Topics (pp.101-24). Chichester - New York: John Wiley.

Marr, D. (1982). Vision: a computational investigation into the human representation and processing of visual information. New York: Freeman. 
Medin, D. \& M. Schaffer (1978). Context theory of classification learning. Psychological Review, 85, 207-38.

Michaels, C. \& C. Carello, C. (1981). Direct Perception. Englewood Cliffs:

New Jersey Prentice-Hall.

Miller, G. (2000). Evolution of human music through sexual selection. In N.L.

Wallin, B. Merker, and S.Brown (eds). The Origins of Music (pp. 329-60).

Cambridge, MA: MIT Press.

Müller, M. (2007). Information Retrieval for Music and Motion. Berlin Heidelberg - New York: Springer.

Nosofsky, R. (1988). Exemplar-based accounts of relations between classification, recognition, and typicality. Journal of Experimental Psychology: Learning, Memory, \& Cognition, 14, 700-708.

Peirce, C. (1960). Elements of Logic. In C.Hartshorne \& P.Weiss (eds), Collected Papers of Ch.S.Peirce. Vol.2. Cambridge (MA): Harvard University Press.

Piaget, J. (1936). La naissance de l'intelligence chez l'enfant. Geneva:

Delachaux et Niestlé.

Piaget, J. (1937). La construction du réel chez l'enfant. Geneva: Delachaux et Niestlé.

Pomerantz, J.R. (1986). Visual form perception: An overview. In E. Schwab \& H. Nusbaum (eds). Pattern recognition by humans and machines: Visual perception (Vol.2, pp. 1-30). Orlando, FL: Academic.

Reti, R. (1961). The Thematic Process in Music. London: Faber \& Faber.

Reybrouck, M. (2001). Biological roots of musical epistemology: Functional

Cycles, Umwelt, and enactive listening. Semiotica, 134, 1-4, 599-633.

Reybrouck, M. (2004). Music Cognition, Semiotics and the Experience of Time. Ontosemantical and Epistemologic Claims. Journal of New Music Research, 33, 4, 411-28. 
Reybrouck, M. (2005a). A Biosemiotic and Ecological Approach to Music Cognition: Event Perception between Auditory Listening and Cognitive Economy. Axiomathes. An International Journal in Ontology and Cognitive Systems, 15, 2, 229-66.

Reybrouck, M. (2005b). Body, mind and music: musical semantics between experiential cognition and cognitive economy. Trans, 9 $<$ http://www.sibetrans.com/trans/

Reybrouck, M. (2006). Musical Creativity between Symbolic Modelling and Perceptual Constraints: the Role of Adaptive Behaviour and Epistemic Autonomy. In I. Deliège \& G. Wiggins (eds). Musical Creativity: Multidisciplinary Research in Theory and Practice (pp. 42-59). Oxford: Psychology Press.

Reybrouck, M. (2008). The Musical Code between Nature and Nurture. In M. Barbieri (ed). The Codes of Life: The Rules of Macroevolution (pp. 395434). Springer: Dordrecht.

Rosenthal, D. \& H. Okuno (1998). Computational auditory scene analysis. Hillsdale (NJ): Erlbaum.

Ruwet, N. (1972). Langage, Musique, Poésie. Paris: Editions du Seuil.

Shaw, R., O. Flascher, \& W. Mace (1996). Dimensions of Event Perception. In W. Prinz \& B. Bridgeman (eds). Handbook of Perception and Action. Volume 1: Perception (pp. 345-395). London - San Diego - New York Boston - Sydney - Tokyo - Toronto: Academic Press, Harcourt Brace. Shaw, R. \& W. Hazelett, (1986). Schemas in Cognition. In V. McCabe \& G. Balzano (eds). Event Cognition: An Ecological Perspective (pp. 45-58). Hillsdale, NJ - London: Lawrence Erlbaum.

Shaw, R. \& J. Pittenger (1978). Perceiving change. In H.L.Pick \& E.Salzman (ed). Modes of Perceiving and Processing Information (pp. 187-204). Hillsdale, NJ: Erlbaum. 
Shepard, R. (1984). Ecological constraints on internal representation: Resonant kinematics of perceiving, imagining, thinking, and dreaming. Psychological Review, Vol. 91 (4), 417-47.

Trehub, S. (2003). Musical predispositions in infancy: an update. In I. Peretz \& R. Zatorre (eds). 2003). The Cognitive Neuroscience of Music (pp. 3-20). Oxford - New York: Oxford University Press, Tversky, A. (1977). Features of similarity. Psychological Review, 84, 327-52.

Wang, D. \& G. Brown (eds) (2006). Computational auditory scene analysis: Principles, Algorithms, and Applications. Hoboken, NJ: IEEE Press/WileyInterscience.

Weiss, P. (1971). Hierarchically Organized Systems in Theory and Practice. New York: Hafner.

Whitehead, A. \& B. Russell (1968). Principia Mathematica, Vol.I. Cambridge: University Press.

Wiggins, G. (2007). Models of musical similarity. Musicae Scientiae, Discussion Forum 4A, 315-37.

Wittmann, M. (1999). Time perception and temporal processing levels of the brain. Chronobiology International, 16, 17-32.

Wittmann, M \& E. Pöppel (1999-2000). Temporal mechanisms of the brain as fundamentals of communication - with special reference to music perception and performance. Musicae Scientiae, Special Issue, 13-28.

Ziv, N. \& Z. Eitan (2007). Themes as prototypes: Similarity judgments and categorization tasks in musical contexts. Musicae Scientiae. Discussion Forum 4A, 3-6, 99-133. 
